\title{
Preface: special issue on catalysis
}

\author{
B. Viswanathan
}

Published online: 25 December 2013

(C) Indian Institute of Technology Madras 2013

The science of catalysis has been undergoing a variety of changes during the last century and the changes that are effected is enormous in the last two or three decades. Even though the science of catalysis is itself interesting to the enquiring mind, it has high application potential and it is normally conceived that more than $90 \%$ of chemical industry employs catalysts in one form or other. The role of the science of catalysis has increased in the last three decades especially from the point of view of energy conversion and environmental concerns.

The concept of energy conversion has undergone considerable change especially during the last two decades with the possibility of harnessing solar energy. In this area in addition to the conventional concerns on photosynthesis and biomass, the concept of photo-electrochemical cells as a device for the conversion of solar radiation into a viable and renewable fuel like hydrogen or conversion of carbon dioxide into useful fuels back has become possible though these have not yet reached the levels of commercial exploitation. Possibly it is only a question of time.

The enquiring mind has always attempted to minic nature since natural processes are the most efficient systems. The concept of photoelectrochemcial cells and photovoltaics are some sort of manifestations of nature's way of storing energy.

Biomass conversion to useful fuels is another way of completing the energy cycle in a sustained manner. In this endeavor the science of catalysis has been contributing

B. Viswanathan $(\bowtie)$

Chennai, India

e-mail: bvnathan@iitm.ac.in considerably in the conversion to biodiesel and also the byproducts formed as a result of transesterification (namely glycerol) can be converted into value added chemicals like 1,2 or 1,3 propanediol, acrolein, and a variety of other products thus paving the way to remove the concept of waste.

Sustainable development is generally defined as "development which meets the needs of the present generation without compromising the ability of the future generations to meet their own needs". The implication of this statement that human endeavor today should enable all people to meet their basic needs and improve their quality of life while ensuring that the natural systems, resources and diversity upon which they depend are maintained and enhanced both for their benefit and for that of the future". In this endeavor, the role of catalysis has to be recognized and practiced appropriately.

In view of the explosive nature of publications in the field of catalysis, the International Journal of Advances in Engineering Sciences and Applied Mathematics has considered it as an opportunity to bring out a special issue on the centre of the field of catalysis namely the active centres where the catalytic action is taking place. Conventionally the concept of active centres itself is broad and wide and can be a priori present or can be generated at the call of the reacting substrates. It is hoped that this will act as a stimulus for further research in this interesting field of catalysis.

In this issue on catalysis, five selected papers have been included to substantiate the frontier activity in this field in India. The issue concentrates on the conversion of biosource materials for fuels and chemicals. The paper by Kannan et al. focuses on the conversion of natural (biomass) materials for biodiesel production while Lingaiah et al. discuss the conversion of value added products like 
5-hydroxy methylfurfural. The paper by Sivasanker et al. deals with the transesterification of sunflower oil, a biosource material for biodiesel. The final two papers in the issue (by Parida and by Reddy et al.) deal with the use of oxide or composite oxide catalysts for fine chemical conversion processes. 